American Journal of Applied Sciences 8 (8): 762-765, 2011

ISSN 1546-9239

(C) 2011 Science Publications

\title{
Intrahydrogen Bonding and Transition States Between Enol and Enethiol Tautomers in $\beta$-Thioxoketones
}

\author{
${ }^{1}$ Bahjat A. Saeed, ${ }^{2}$ Rita S. Elias and ${ }^{3}$ Ebraheem Abdu Musad \\ ${ }^{1}$ Department of Chemistry, College of Education, \\ ${ }^{2}$ Department of Pharmaceutical Chemistry, College of Pharmacy, \\ University of Basrah, Iraq \\ ${ }^{3}$ Department of Studies in Chemistry, University of Mysore, \\ Manasagangotri, Mysore 570006, India
}

\begin{abstract}
Problem statement: Hydrogen bonding is one of the most important concepts in chemistry because it is crucial to understand many different interactions both in gas phase and in condensed media. A particular subset is presented by the intramolecular hydrogen bonds where two ends of the same molecule interact, resulting in a ringlike structure. Approach: The study involved theoretical investigation of proton transfer and transition states in $\beta$-thioxoketones. Both structures of the enol and enethiol tautomers of $\beta$-thioxoketones were geometrically optimized then the transition states were obtained. The calculations were done at the B3LYP hybrid and 6-31G(d,p), 6-31+G(d,p), 6$31++\mathrm{G}(\mathrm{d}, \mathrm{p}), 6-311 \mathrm{G}(\mathrm{d}, \mathrm{p}), 6-311+\mathrm{G}(\mathrm{d}, \mathrm{p})$ and $6-311++\mathrm{G}(\mathrm{d}, \mathrm{p})$ basis sets. Results: The calculated energies of the enethiol tautomer are higher than those of the enol tautomer for all the thioxoketones studied in this work. The S...O distances are in the order: enethiol > enol > transition state in addition the hydrogen bonding in the enol tautomer is stronger than that in the enethiol tautomer. Conclusion: The interconversion within the tautomeric mixture in these compounds is preferable in the enethiol $\rightarrow$ enol direction.
\end{abstract}

Key words: $\beta$-thioxoketones, density functional theory, intrahydrogen bonding, reaction barrier, Transition State (TS), tautomeric mixture, basis sets, enethiol, ringlike structure, isolatedmolecule conditions, harmonic analyses

\section{INTRODUCTION}

$\beta$-Thioxoketones are of particular interest as model compounds for studies of prototropic tautomerism and intramolecular hydrogen chelating properties (Gonzalez et al., 1999; Gonzalea et al., 1997) and tautomeric and photochromic behavior (Hansen et al., 2007; Goeski, et al., 2007), are among the most conducted studies on $\beta$ Thioxoketones. Carlsen and Duus (1979) were the first to investigate the photo reactivity of $\beta$-Thioxoketones and concluded that the photoprocess was best interpreted as the transformation of an initial enol tautomeric form exhibiting a strong intramolecular hydrogen bond into enethiolic counterpart.

The presence of a strong intramolecular hydrogen bond that adjoins hydroxylic (proton-donating) and ketonic (proton-accepting) oxygen and sulpher centers markedly stabilizes the enolic tautomers causing them to dominate over their diketo counterparts under ambient, isolated-molecule conditions (Nguyen et al., 2006; Andersen et al., 2000; Posokhov et al., 2001) as is the case of their structurally related compounds, $\beta$ diketones (Chatterjee et al., 2010; Yamabe et al., 2004). Jorgensen et al. (1981) on the basis of photoelectron spectroscopic and theoretical study for thioacetylacetone and related compounds concluded that simple $\beta$-Thioxoketones exist as equilibrium mixtures of rapidly interconverting intramolecularly hydrogen bonded enol and enethiol tautomeric forms.

An ab initio study using the HF/6-31G(d,p) level for the thioketo-thioenol tautomerism of dithiomolandialdehyde and dithioacetylacetone reveled that all of the enethiol conformers of dithiomolandialdehyde were found to be more stable than the keto conformers, eventhough the chelate structures are expected to be less stable than the most of the unchelated isomers. The hydrogen bonded dithioacetylacetone was predicted to be energetically favoured with respect to the other enethiol isomers, but a non-planar thioketo structure is found to be the most stable conformation (Buemi, 1992). A theoretical study on thiodibenzoylmethan using B3LYP/cc-pVTZ level of theory revealed that the stable ground state 
conformation corresponds to the intramolecularly hydrogen-bonded enol form (Hansen et al., 2007).

In this study we investigate the transition states of the equilibrium reaction enol-enethiol and the effect of intrahydrogen bonding in $\beta$-thioxoketones.

\section{MATERIALS AND METHODS}

The theoretical treatment of the studied molecules utilized quantum chemical methods available in the Firefly software. Geometry optimization procedures and transition state calculations for thiomalonaldehyde were built upon Density Functional Theory (B3LYP) with several basis sets including: 6-31G(d,p), 6$31+\mathrm{G}(\mathrm{d}, \mathrm{p}), 6-31++\mathrm{G}(\mathrm{d}, \mathrm{p}), 6-311 \mathrm{G}(\mathrm{d}, \mathrm{p}), 6-311+\mathrm{G}(\mathrm{d}, \mathrm{p})$ and $6-311++\mathrm{G}(\mathrm{d}, \mathrm{p})$, while the basis set $6-31 \mathrm{G}(\mathrm{d}, \mathrm{p})$ was used for other molecules. The nature of each optimized structure was confirmed by performing harmonic analyses of the vibrational force field.

\section{RESULTS}

No imaginary frequencies were found in the calculated vibrational spectra of the stable enol and enethiol structures, while a single imaginary stretching frequency (essential coincident with the S...H...O reaction coordinate) was found for each Transition State (TS). The energies for the enol, enethiol and transition states are summarized in Table 1. The energies are sensitive to the basis set used. On the other hand the transition states are characterized by their higher energies compared to both tautomres. Table 2 shows energies, relative energies and reaction barriers for the $\beta$-thioxoketones studied. In all cases the energy of the enethiol is higher than the energy of the enol tautomer. Table 3 shows the donor-acceptor distances for the tautomers and the transition states.

\section{DISCUSSION}

Figure 1 presents an overview of the proton transfer process in enolic thiomalonaldehyde at the B3LYP/6-311++G(d,p) level of theory, in addition to the structural properties of the three species enethiol, Transition state and the enol.

Table 1 summarizes energy calculation performed on the ground electronic states of enethiol and enol tautomers. It is clear that the calculated values of the energies depend on the basis set used. Accordingly the energy increases from -590.11527029 and -590.120723 hartree for the enethiol and the enol respectively at the B3LYP/6-31G(d,p) level to -590.19722694 and 590.20125758 hartree at the B3LYP/6-311++G(d,p) level.

On the other hand and in all cases the energy of the enol tautomer is lower than that of the enethiol tautomer indicating that the former species is the more stable. Table 2 shows that the reaction barrier in the direction enethiol $\rightarrow$ Transition state $\left(749.5 \mathrm{~cm}^{-1}\right)$ is much more lower than that in the direction enol $\rightarrow$ Transition state $\left(1946.2 \mathrm{~cm}^{-1}\right)$ which means that interconversion between the enol and enethiol tautomers is preferable in the direction enethiol $\rightarrow$ enol. This is in accordance with the experimental results that found the tautomer enol is the predominant tautomer within the equilibrium mixture of the tautomers (Chatterjee et al., 2010; Yamabe et al., 2004; Jorgensen et al., 1981).

Table 1: Total energies of enol. enethiol and transition state for thiomalonaldehyde (hartree)

\begin{tabular}{llll}
\hline Theoretical level & $\mathrm{E}_{\text {enol }}$ & $\mathrm{E}_{\text {enethiol }}$ & $\mathrm{E}_{\text {transition state }}$ \\
\hline B3LYP/6-31G(d,p) & -590.12072341 & -590.11527029 & -590.11185541 \\
B3LYP/6-31+G(d,p) & -590.13110841 & -590.12649208 & -590.12257368 \\
B3LYP/6-31++G(d,p) & -590.13126317 & -590.12661680 & -590.12272464 \\
B3LYP/6-311G(d,p) & -590.19623721 & -590.19150848 & -590.18699742 \\
B3LYP/6-311+G(d,p) & -590.20112295 & -590.19709362 & -590.19219335 \\
B3LYP/6-311++G(d,p) & -590.20125758 & -590.19722694 & -590.19231569 \\
\hline
\end{tabular}

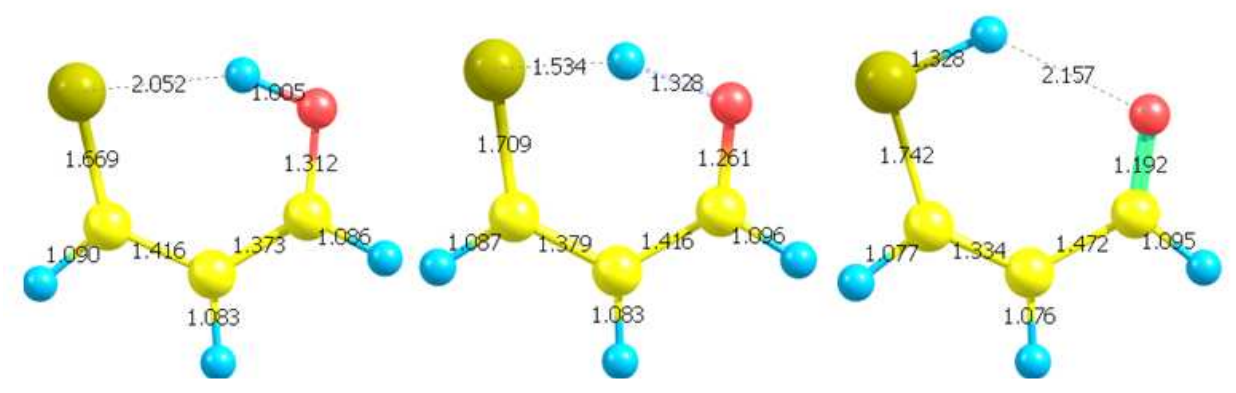

Fig. 1: Proton transfer process in enolic thiomalonaldehyde 
Am. J. Applied Sci., 8 (8): 767-765, 2011

Table 2: Total energies (hartree), relative energies $\left(\mathrm{cm}^{-1}\right)$ and reaction barriers $\left(\mathrm{cm}^{-1}\right)$ of the studied $\beta$-thioxoketones calculated at B3LYP/6$31 \mathrm{G}(\mathrm{d}, \mathrm{p})$ level of theory

\begin{tabular}{|c|c|c|c|c|c|c|c|}
\hline \multirow[b]{2}{*}{$\mathrm{R} 1$} & \multirow[b]{2}{*}{$\mathrm{R} 2$} & \multirow[b]{2}{*}{ enol } & \multirow[b]{2}{*}{ enethiol } & \multirow[b]{2}{*}{ Transition state } & \multirow[b]{2}{*}{ Relative energy } & \multicolumn{2}{|c|}{ Reaction barrier } \\
\hline & & & & & & Enol $\rightarrow$ TS & Enethiol $\rightarrow \mathrm{TS}$ \\
\hline $\mathrm{H}$ & $\mathrm{H}$ & -590.12072341 & -590.11527029 & -590.11185541 & 1196.2 & 1946.4 & 749.5 \\
\hline $\mathrm{Me}$ & $\mathrm{H}$ & -629.44382458 & -629.43876311 & -629.43618721 & 1110.9 & 1676.2 & 565.3 \\
\hline $\mathrm{H}$ & $\mathrm{Me}$ & -629.44942984 & -629.44325633 & -629.44030747 & 1354.9 & 2002.1 & 647.2 \\
\hline $\mathrm{Me}$ & $\mathrm{Me}$ & -688.86110463 & -668.76634838 & -668.74125880 & 2096.6 & 2128.4 & 487.9 \\
\hline $\mathrm{Ph}$ & $\mathrm{H}$ & -821.18445981 & -821.17968865 & -821.17784169 & 1047.1 & 1452.5 & 405.4 \\
\hline $\mathrm{H}$ & $\mathrm{Ph}$ & -821.19191542 & -821.18552080 & -821.18336632 & 1403.5 & 1876.3 & 472.9 \\
\hline $\mathrm{Ph}$ & $\mathrm{Me}$ & -860.51429258 & -860.50700305 & -860.50561461 & 1599.9 & 1904.6 & 304.7 \\
\hline $\mathrm{Ph}$ & $\mathrm{Ph}$ & -1052.25356737 & -1052.24930426 & -1052.24833906 & 935.7 & 1147.5 & 211.8 \\
\hline
\end{tabular}

Table 3: Donor-acceptor distances (S...O distance) for the studied $\beta$-thioxoketones $(\AA)$

\begin{tabular}{|c|c|c|c|c|c|c|}
\hline \multirow[b]{2}{*}{$\mathrm{R} 1$} & \multirow[b]{2}{*}{ R2 } & \multirow[b]{2}{*}{ enethiol } & \multirow[b]{2}{*}{ enol } & \multirow[b]{2}{*}{ TS } & \multicolumn{2}{|c|}{ Reaction change } \\
\hline & & & & & Enethiol-TS & Enol-TS \\
\hline $\mathrm{H}$ & $\mathrm{H}$ & 3.050 & 2.968 & 2.798 & 0.252 & 0.170 \\
\hline $\mathrm{Me}$ & $\mathrm{H}$ & 3.012 & 2.937 & 2.795 & 0.217 & 0.142 \\
\hline $\mathrm{H}$ & $\mathrm{Me}$ & 3.027 & 2.952 & 2.802 & 0.225 & 0.149 \\
\hline $\mathrm{Me}$ & $\mathrm{Me}$ & 2.990 & 2.910 & 2.792 & 0.198 & 0.118 \\
\hline $\mathrm{Ph}$ & $\mathrm{H}$ & 2.997 & 2.916 & 2.800 & 0.197 & 0.116 \\
\hline $\mathrm{H}$ & $\mathrm{Ph}$ & 3.001 & 2.935 & 2.796 & 0.205 & 0.139 \\
\hline $\mathrm{Ph}$ & $\mathrm{Me}$ & 2.976 & 2.917 & 2.806 & 0.170 & 0.111 \\
\hline $\mathrm{Ph}$ & $\mathrm{Ph}$ & 2.950 & 2.868 & 2.799 & 0.151 & 0.079 \\
\hline
\end{tabular}

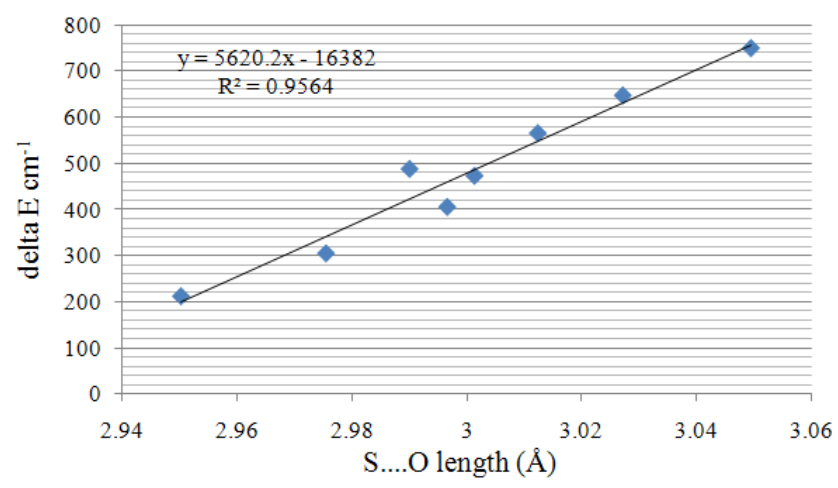

Fig. 2: Correlation between $\mathrm{r}_{\mathrm{S} . . . \mathrm{O}}$ and the enethiol $\rightarrow$ transition state energy barrier

Table 2 summarizes the energies, relative energies and reaction barriers for the studied molecules. The same conclusion could be drawn concerning the relative stabilities of the enol and enethiol tautomers, in all molecules the most stable tautomer is the enol. For example, the energies calculated for the enol and the enethiol species at B3LYP/6-31G(d,p) level in the case of thioacetylacetone are -668.76634838 and 668.86110463 hartree respectively, while for thiodibenzoylmethane, these energies are 1052.25356737 and -1052.24930426 hartree respectively.

Table 3 highlight the inter oxygen-sulpher donoracceptor distances calculated for the enethiol, enol and the transition state geometries for thiomalonaldehyde and its analogues, as well as the variation in this quantity taking place along the $\mathrm{S}-\mathrm{H} \ldots \mathrm{O} \leftrightarrow \mathrm{S} . . \mathrm{H}-\mathrm{O}$ reaction coordinate.

In all cases the $r_{S \ldots O}$ distance in the enethiol is longer than that for enol indicating that the intrahydrogen bonding in the enol form is stronger than that in the enethiol tautomer. This may account for its relative higher stability. For the transition state this distance is the shortest among the transition mixture which explains its higher energy due to the electrostatic repulsion between the sulpher and the oxygen atoms. The reaction barriers values (Table 2) and the $r_{S \ldots O}$ values in the enethiol tautomer (Table 3) indicate a correlation relationship between these variables. This is shown schematically in Fig. 2, with regression coefficient value of 0.956 . 
It is evident that the lower the $r_{S \ldots O}$ value (the stronger intrahydrogen bonding) the lower the reaction barrier is. This is clear when comparing the cases of thiodibenzoylmethane which have the shortest $r_{S . . . O}$ value $(2.950 \AA)$ and thiomalonaldehyde which have the longest $r_{S . . . O}$ value $(3.050 \AA)$. From Table 2 the reaction barriers are 211.8 and $749.5 \mathrm{~cm}^{-1}$ respectively. This suggests that $\beta$-thioxoketones with stronger intramolecular hydrogen bonding have more tendencies to be in the enol form.

\section{CONCLUSION}

It could be concluded from this study that the enol tautomer is the most stable tautomer in the equilibrium mixture the of $\beta$-thioxoketones. In addition interconversion between the enol and enethiol tautomers is preferable in the direction enethiol $\rightarrow$ enol since the enethiol $\rightarrow$ transition state barrier is lower than the enol $\rightarrow$ transition state barrier.

\section{REFERENCES}

Andersen, B., F. Duus, S. Bolvig and P.E. Hansen, 2000. Variable temperature $1 \mathrm{H}$ and $13 \mathrm{C}$ spectroscopic investigation of the enol-enethiol tautomerism of $\beta$-thioxoketones. Isotop effects due to deuteron chelation. J. Mol. Struct., 552: 45-62. DOI: 10.1016/0166-1280(92)850982-k

Buemi, G., 1992. Ab initio study of the thioketothioenol tautomerism of dithiomalondialdehyde and dithioactylacetone. J. Mol. Struct., 257: 243257. DOI: $10.1016 / 0166-1280(92) 85043-\mathrm{k}$

Carlsen, L. and F. Duus, 1979. $\beta$-Thioxo-ketones. Part 5. Photo-induced enol-enethiol interconversion of $\beta$-thioxo-ketones. J. Chem. Soc., Perkin Trans., 2: 1532-1534 DOI: 10.1039/P29790001532

Chatterjee, Ch., Ch.D. Incarvito, L.A. Burns and P.H. Vaccaro, 2010. Electronic structure and proton transfer in ground-state hexafluoroacetylacetone. J. Phys. Chem., 114: 6630-6640. DOI: 10.1021/jp101224e
Goeski, A., Y. Psokhov, B.K.V. Hansen, J. SpangetLarsen and J. Jasny et al., 2007. Photochromism in p-methylbenzoylthioacetone and related $\beta$ hioxoketones. Chem. Phys., 338: 11-22. DOI: 10.1016/j.chemphys.2007.07.030

Gonzalea, L., O. Mo and M. Yanez, 1997. High-level $\mathrm{ab}$ initio calculations on the intramolecular hydrogen bond in thiomalonaldehyde. J. Phys. Chem., 101: 9710-9719. DOI: 10.1021/jp970735z

Gonzalez, L., O. Mo and M. Yanez, 1999. Substituent effects on the strength of the intramolecular hydrogen bond of thiomalonaldehyde. J. Org. Chem., 64: 2314-2321. DOI: 10.1021/jo981982h

Hansen, B.K.V., A. Gorski, Y. Posokhov, F. Duus and P.E. Hansen et al., 2007. Monothiodibenzoylmethane: structure and vibrational assignments. Vibrational Spectrosc., 43: 53-63. DOI: 10.1016/j.vib.spec.2006.06.015

Jorgensen, F. S., L. Carlsen and F. Duus, 1981. The electronic structure of $\beta$-thioxoketones. A photoelectron spectroscopic study of enol-enethiol tautomerism of thioacetylacetone and related compounds. J. Am. Chem. Soc., 103: 1350-1353. DOI: $10.1021 / \mathrm{ja00396a008}$

Nguyen, T.T., T.N. Le, P.E. Hansen and F. Duus, 2006. Preparation and structure characterization of new class of stable thioketones and orthohydroxythioacetophenones. Tetrahedron Lett., 47: 8433-8435. DOI: 10.1016/j.tetlet.2006.09.033

Posokhov, Y., A. Gorski, J. Spanget-Larsen, F. Duus, P. E. Hansen and J. Waluk, 2001. The structure of phototransformation product of monothidibenzoylmethane. Chem. Phys. Lett., 350: 502-508. DOI:

Yamabe, Sh., N. Tsuchida and K. Miyajima, 2004. Reaction paths of keto-enol tautomerism of $\beta$ diketones. J. Phys. Chem., 108: 2750-2757. DOI: 10.1021/jp031243r 